\title{
Compliment Behavior: A Case Study of Burmese from Lower Myanmar
}

\author{
Winn Myintzu ${ }^{1}$ \\ ${ }^{1} \mathrm{PhD}$ Student in English Applied Linguistics Programme, University of Szeged, Hungary \& \\ Lecturer, Department of English, National Management Degree College, Yangon, Myanmar
}

\begin{abstract}
This paper provides an overview of the compliment behaviors of Burmese people living in lower Myanmar. Burmese people generally pay compliments to their friends and family members most. They pay compliments to these people quite often, and their compliments are especially for the complimentees' ability and personality. Burmese people's compliment responses are based on the relationship between the complimenter and the complimentee. Sincerity is the most influential factor in compliment responses as well as complimenting others.
\end{abstract}

Keywords: Burmese, Myanmar, compliment, compliment behavior, compliment response

\section{Introduction}

Every day in our life, we receive compliments from others; on the other hand, we pay compliments to others. A compliment is defined by Holmes (1988) as 'an utterance referring to something which is positively valued by the participants and attributed to the addressee.' She also explains that a compliment is 'a speech act which explicitly or implicitly attributes credit to someone other than the speaker, usually the person addressed, for some 'good' (possession, characteristic, skill, etc.) which is positively valued by the speaker and the hearer.' Compliment behavior of one community may differ from that of another community. Even different people in the same community may have different compliment behaviors.

\subsection{Significance of the study}

Only limited numbers of studies on the compliment behavior of people from Southeast Asian countries can be found in the literature. And, there is no empirical study on Burmese compliment behavior. Therefore, the present study is significant in understanding compliment behavior of Burmese people.

\subsection{Aim of the study}

There is ample research on Chinese compliment (a few Chinese studies on the topic) not only by Chinese scholars but also by those from the Western world. However, as mentioned above, there are very few works of literature on the compliment responses of the Southeast Asian culture and there is no literature on Burmese compliment responses at all. This study is to fill a gap in the literature on compliment responses of Burmese people. The present study investigates not only the compliment responses of Burmese people but also the complimenting behavior of these people.

Earlier studies on compliment responses investigate that compliment responses in East and West cultures are totally different. English speakers use 'Acceptance' much more than 'Rejection' whereas Chinese people use 'Rejection' as a routinized response to a compliment in their culture. However, the recent studies on Chinese compliment responses show that Chinese compliment responses become more and more similar to those of 
Western cultures and Chinese complimentees tend towards 'Acceptance' strategies rather than 'Rejection' strategies in response to a compliment.

The present study is to examine the compliment behavior of Burmese people who live in the lower Myanmar with the following research questions:

1) What is the complimenting behavior of the Burmese people in this study including to whom, how often and for what they most frequently pay compliments to others?

2) How do Burmese people in the present study respond to the compliments they receive?

\section{Theoretical Framework}

The speech acts of compliment and compliment responses are conversational devices of interpersonal relationships in daily life. (Tang \& Zhang, 2009) To every compliment, there is a compliment response which is 'a verbal acknowledgment that the recipient of the compliment heard and reacted to the compliment'. (Nelson, et. al., 1996). According to Pomerantz (1978), there are two conflicting concerns for the complimentees when they receive compliments: to agree with the complimenter ('Acceptance' often with an appreciation token of 'Thank you') or to avoid the compliment ('Rejection' by downgrading the value of the object of the compliment or shifting the credit away from the responder herself). Chen $(1993,2010)$ asserts that complimentees always use 'Acceptance' strategy, which is motivated by Leech's (1983) Agreement Maxim, as the compliment is a form of positive politeness. He also states that 'Rejection', which is motivated by Leech's Modesty Maxim, can be a face-threatening act. If the complimentee upholds the Agreement Maxim, he/she may flout the Modesty Maxim. On the other hand, if he/she upholds the Modesty Maxim, he/she may flout the Agreement Maxim. Different people respond to compliments differently according to their societies' traditional values and norms of interaction. (Shaari \& Maros, 2017)

Many scholars study compliment responses of different cultures. For English Speakers, 'Acceptance' is much more common than 'Rejection' and they rarely reject or disagree with a compliment. 'Rejection' of compliments is often regarded as a symptom of a problem, such as low self-esteem. (Pomerantz, 1978) When studies are done for the compliment responses of the East culture, scholars compare Chinese compliment responses with that of the Western world. According to Ye (1995 quoted in Spencer-Oatey et. al., 2008), 'Rejection' is a routinized response to a compliment in Chinese culture. Regarding Chinese compliment responses, Chen (1993) and Ye (1995 quoted in Spencer-Oatey et. al., 2008) write that the best response is a rejection or denial followed by self-denigration. This is motivated by the Modesty Maxim, 'minimizing praise of self' and 'maximizing dispraise of self'. (Chen, 1993) No matter how pleased or how much in agreement the complimentee is, he/she should deny it or scale it down to show modesty. (Su, 1992 quoted in Guo et. al., 2012) From these studies, it can be said that the compliment responses in East and West cultures are totally different. However, recent studies on Chinese compliment responses show that Chinese people's compliment responses become more and more similar to those in Western cultures and Chinese complimentees tend towards 'Acceptance' strategies rather than 'Rejection' strategies in response to a compliment. Their responses gradually begin to run counter to Chen (1993) and Ye's (1995 quoted in Spencer-Oatey et. al., 2008) findings of 'Rejection' being preferred by the Chinese complimentees. (Yuan, 2002; Chen, 2003; Cheng, 2011 and Guo, et. al., 2012) According to Yuan (2002), the change is probably because of western influence through movies and the media. Another change is found in the studies by Tang \& Zhang (2009) and Guo et. al. (2012). The participants in their studies use 'combined types of strategies' when responding to compliments.

\section{Data Collection and Analysis}

In the present study, a questionnaire is used to investigate the compliment behavior of Burmese people. The questionnaire is based on the one in Spencer-Oatey et. al. (2008, pp. 114-115). It was translated into Burmese and adapted according to the Burmese culture. As in Spencer-Oatey's, five scenarios with someone's successful performance or achievement in each, are mentioned and there are five different responses in each scenario: two acceptance responses, two rejection responses, and one deflection response. Two acceptance responses are 'Explicit Acceptance' and 'Appreciation Token - Thanks/Thank you.'. Among the two rejection responses, one is 'Explicit Rejection' and the other is 'Rejection Rejoinder - No, you're flattering me.' Different responses are 
used for 'Deflection' in different scenarios. The relationship between the complimenter and the complimentee in each scenario is different: teacher-student, close friends, mother-son, strangers, and unfamiliar peers.

In the study, there are 70 subjects who are Burmese people ( $n=70 ; 20$ male and 50 female, age 16-52), living in Lower Myanmar. The questionnaire was distributed electronically to all the Burmese people living in lower Myanmar whom the researcher knows. In addition, interviews with some of the respondents are conducted for further clarification. The data from this systematic survey is analyzed in terms of descriptive statistics (Tally and Percentage).

\section{Results}

\subsection{Complimenting behaviors in Burmese culture}

In the study, it is found that Burmese people pay their compliments to their friends and family members most. On the other hand, they pay their compliments to their superiors and strangers least. As in TABLE 1, $84.28 \%$ of the respondents in this study report that they pay their compliments to their friends. $61.42 \%$ report that they pay their compliments to their family members. $50 \%$ of the respondents in the study report that they also pay compliments to children and $47.14 \%$ of the respondents report that they also pay compliment to their colleagues. $41.42 \%$ of the respondents report that they pay compliment to their acquittance as well. $34.28 \%$ of the respondents pay their compliments to their acquittance, and $25.71 \%$ of the respondents pay their compliments to their relatives. Respondents in the study also report that they pay their compliments to their superiors and strangers as well, but only $17.14 \%$ of the respondents report so.

TABLE I: To Whom Burmese People Pay Compliments

\begin{tabular}{cc}
\hline Whom & Percentage \\
\hline Friends & $84.28 \%$ \\
Family members & $61.41 \%$ \\
Children & $50 \%$ \\
Colleagues & $47.14 \%$ \\
Acquaintances & $41.42 \%$ \\
Teachers & $34.28 \%$ \\
Relatives & $25.71 \%$ \\
Superiors & $17.14 \%$ \\
Strangers & $17.14 \%$ \\
& \\
\hline
\end{tabular}

Regarding how often Burmese people pay compliments, 30 respondents in the study report that they often pay compliments whereas 25 respondents report that they sometimes pay compliments. 6 respondents report that they always pay compliments while another 6 respondents report that they seldom pay compliments. 3 respondents report that they pay compliments to others whenever the complimentee does something good, or whenever they envy the complimentee. Therefore, it is found in the study that Burmese people often pay compliments to others.

Regrading for what Burmese people pay compliments to others, it is found that 64 out of 70 respondents pay their preferential to others for the complimentee's ability whereas 43 respondents pay their compliments to 
others for the complimentee's personality. 25 respondents report that they pay compliments to others for their appearance and 24 respondents report that they pay compliments for the complimentee's clothes. Therefore, the present study shows that Burmese people's compliment is mostly for the complimentee's ability.

It is also investigated in the study that for 60 respondents, sincerity is the most influential factor in complimenting others. Very few respondents report that they sometimes lie while complimenting others. Among them, some report that they want to motivate the complimentee to do something, or not to feel down while other respondents report that they pay compliments as their social skill. Some respondents report that sometimes, a person around them needs a compliment that can encourage him/ her for future work. In that kind of situation, their compliment does not reflect their genuine opinion. Some respondents report that whether their compliment reflects their genuine opinion or not depends on the relationship between the complimentee and them. If the relationship is very close, the compliment depends on sincerity, but if not, the compliments are sometimes not true.

\subsection{Compliment responses in Burmese culture}

In the analysis of the data from the survey, it is found that Burmese people in the survey use more 'Acceptance' (218 responses) than 'Rejection' (59 responses) as their compliment responses in the 5 situations of the survey. For the 'Acceptance' responses, they use more 'Acceptance Rejoinder' (133 responses) than 'Explicit Acceptance' (85 responses). (See TABLE 2)

Although Burmese people in this study generally prefer 'Acceptance', 'Deflection' (176 responses) is found as the respondents' most used strategy among the 5 types of compliment responses in this present study. The one the respondents used least was 'Rejection Rejoinder' (18 responses). (See TABLE 2)

TABLE II: Number of Specific Compliment Response Strategies

\begin{tabular}{llc}
\multicolumn{2}{c}{$\mathrm{N}=453(100 \%)$} & Quantity \\
\hline \multirow{3}{*}{ Acceptance } & Explicit Acceptance & $85(18.76 \%)$ \\
\cline { 2 - 3 } & Acceptance Rejoinder & $133(29.35 \%)$ \\
\hline \multirow{2}{*}{ Rejection } & Explicit Rejection & $41(9.05 \%)$ \\
\cline { 2 - 3 } & Rejection Rejoinder & $18(3.97 \%)$ \\
\hline & Deflection & $176(38.85 \%)$
\end{tabular}

As there are 5 situations tested to investigate Burmese compliment responses, and the number of respondents in this study is 70, the total number of compliment responses should be 350 . However, there are altogether 453 responses in the survey since some respondents use 'Combined Strategies' in their responses. However, the use of 'Combined Strategies' is not as much as that of 'Single Strategies' in the present study. Specifically, 16 respondents in Situation 1 (where the complimenter is their teacher), 15 respondents in Situation 2 (where the complimenter is their close friend), 14 respondents in Situation 3 (where the complimenter is their mother), and 29 respondents each in Situation 4 (where the complimenter is a stranger) and in Situation 5 (where the complimenter is their fellow student) use 'Combined Strategies' in their compliment responses. For example, one of the respondents uses 'Acceptance Rejoinder' and 'Deflection' as his/her compliment response for Situation 1.

The present study also reports that Burmese people's compliment responses are based on the relationship between the complimenter and the complimentee. Their strategy use of compliment responses depends on from whom the compliment comes. If the compliment is from the complimentees' teachers, 'Acceptance Rejoinder' is most used. In the survey, 59.3\% of the respondents use 'Appreciation Token - Thanks/Thank you.' with their teachers. If the complimenter is their friends, the complimentees use 'Deflection' most. $68.23 \%$ of the 
respondents in the survey report that they use 'Deflection' with their close friends. With the family members like mother, it is found that $42.85 \%$ of the respondents in this survey use 'Explicit Acceptance'. If the complimenter is a stranger, the complimentees use 'Explicit Rejection' most. 37.37\% of the respondents in the survey report that they use 'Explicit Rejection' with a stranger. With fellow students, the most used strategy is 'Deflection'. It is found that $55.55 \%$ of the respondents use this strategy with their fellow students. (See TABLE 3)

TABLE III: Percentage of Respondents Who Used Particular Strategy to Particular Complimenter

\begin{tabular}{lccccc}
\hline & Teacher & Close Friend & Mother & Stranger & Fellow Student \\
\hline Explicit Acceptance & $12.79 \%$ & $7.05 \%$ & $42.85 \%$ & $22.22 \%$ & $10.1 \%$ \\
Acceptance Rejoinder & $59.30 \%$ & $16.47 \%$ & $21.42 \%$ & $20.2 \%$ & $30.3 \%$ \\
Explicit Rejection & $1.16 \%$ & $2.35 \%$ & $0 \%$ & $37.37 \%$ & $1.01 \%$ \\
Rejection Rejoinder & $4.65 \%$ & $5.88 \%$ & $7.14 \%$ & $0 \%$ & $3.03 \%$ \\
Deflection & $22.09 \%$ & $68.23 \%$ & $28.57 \%$ & $20.2 \%$ & $55.55 \%$ \\
\hline
\end{tabular}

As seen in TABLE 3, one finding in the present study is that 'Deflection' is most used not only with friends but also with fellow students. Another finding is that 'Rejection Rejoinder - No, you're flattering me.' is seldom used by the complimentees. This strategy is also the least used strategy, and very few respondents use it as a compliment response no matter who the complimenter is.

Regarding factors influencing on Burmese people's compliment responses, the respondents in the present study report that their compliment response reflects their sincerity. 50 out of 70 respondents $(71.42 \%)$ in the survey report that sincerity is the most important factor for them when they respond to compliments by others. Some respondents (27 out of 70 respondents i.e. $38.57 \%$ ) report that modesty also plays a role in their compliment responses. 13 out of 70 respondents (18.57\%) report that sometimes, they want to uphold the other person's face by agreeing with his/her compliment. However, the most influential factor in their compliment responses is their sincerity.

\section{Discussion}

One of the findings in the present study is that Burmese people pay their compliments to their friends and their family members most. However, the frequency of their compliments is not very high. Nearly half of the respondents mention that they often pay compliments to others, and about one-third of the respondents sometimes pay compliments. Regarding what they pay a compliment to others, it is found that Burmese people's compliment is for the complimentee's ability most, but they also pay a compliment for the complimentee's personality. When complimenting others, sincerity is the most influential factor. Most respondents report that their compliments reflect their genuine opinion.

Regarding compliment responses in Burmese culture, Burmese people generally prefer 'Acceptance' to 'Rejection'. This is in line with Pomerantz's (1978) finding for English speakers' compliment responses: 'Acceptance' is much more common than 'Rejection'. Instead of 'Rejection', Burmese speakers in the study use many instances of 'Deflection', and 'Deflection' is found as the most frequently used compliment response strategy in the present study. Another finding of the study is in line with that of Tang \& Zhang (2009), and Guo et. al. (2012) which are about Chinese compliment responses: the speakers used 'Combined strategies' when responding to compliments. In the study, it is found that Burmese speakers use not only 'Single strategies' but also 'Combined strategies' as compliment responses.

Another finding is that compliment responses depend on the relationship between the complimenter and the complimentee. This finding is in line with Gajaseni's (1994, 1995 quoted in Chen, 2010) study on Thai's compliment responses. He states that Thai's compliment responses are influenced by the relationship between the complimenter and the complimentee. However, specifically, the relationship Thai people pay attention to in responding to compliments and the one Burmese speakers in the present study concern are different. According to Gajaseni, Thai compliment responses depend on the social status but for Burmese speakers, it is intimacy. In the present study, it is found that Burmese speakers use 'Deflection' most with their 'close friend' or 'fellow student', and 'Explicit Acceptance' most with their mother, and 'Acceptance Rejoinder' most with their 'teachers'. With a 'stranger', they use 'Explicit Rejection' most. In addition, no respondents use 'Explicit 
Rejection' with their 'mother', and very few respondents use this strategy with their 'teacher', 'close friend', or 'fellow student'. And, they never use 'Rejection Rejoinder' if the complimenter is a 'stranger'.

\section{Conclusion}

As complimenting behavior of the Burmese people living in lower Myanmar, the present study shows that my Burmese participants pay compliments most often to their friends and family members and especially on the complimentees' ability and personality. It has also been demonstrated in the study that sincerity is the most influential factor in complimenting others.

Regarding compliment responses, my Burmese respondents prefer 'Acceptance' strategy and 'Deflection' to 'Rejection'. 'Deflection' is the most used compliment response strategy. Burmese speakers also use 'Combined strategies' in responding to the compliments they receive. Their compliment responses depend on their relationship with the complimenter. 'Appreciation Token - Thanks/Thank you.' which is 'Acceptance Rejoinder' is most used with the teachers, 'Deflection' is most used with friends and fellow students, 'Explicit Acceptance' is most used with the mother, and 'Explicit Rejection' is most used with strangers. The Burmese participants never used 'Rejection Rejoinder - No, you're flattering me.' with strangers, but they seldom used this strategy with others like the mother. On the other hand, they did not use 'Explicit Rejection' with their 'mother', and very few respondents used this strategy with their 'teacher', 'close friend', or 'fellow student'. The most influential factor in responding to compliments by others is 'sincerity'.

Myanmar is an ethnically as well as linguistically diverse country. It is the second-largest country in Southeast Asia, and since under British domination, the country has been referred to as 'upper Myanmar (Burma)' and 'lower Myanmar (Burma)'. In the present study, the data was collected only from people living in lower Myanmar. Moreover, the data in the study was elicited from the respondents, sometimes direct contact with some respondents by asking questions. In the present study, nearly half of the respondents are young aged under 20, and among 70 respondents, only 20 are male. Therefore, it is difficult to say that the compliment behavior in the study represents that of Burmese speakers, and the results in the study represent only the compliment behavior of people in lower Myanmar and especially that of younger generation. If more middleaged and older generations participate in the study, and/or if there are more male participants, the results may be different. Again, if the study is done with not only people from lower Myanmar but also those from upper Myanmar, and if the data is from spontaneous responses, the results may also be different from the ones found in the present study.

\section{Acknowledgments}

The author is indebted to Dr. Malgorzata Suszczyńska and reviewers for their invaluable suggestions and insights. Any errors are my own and should not tarnish their reputations. Thanks also go to all the subjects in this study for their participation and input. Without them, this paper would not have been possible.

\section{References}

[1] A. H. Shaari, and M. Maros. (2017). Compliments and compliment responses across borders: Language and cultural change among the new generation of Malays. Journal of Social Sciences and Humanities. [Online] 12(1). pp. $29-42$. Available: http://ejournal.ukm.my/ebangi/article/view/18390/5802

[2] A. Pomerantz, "Compliment Responses: Notes on the Co-operation of Multiple Constraints," in Studies in the Organization of Conversational Interaction, J. Schenkein, Ed. New York: Academic Press, 1978, ch. 3, pp. 79-112. https://doi.org/10.1016/B978-0-12-623550-0.50010-0

[3] C. Tang, and G. Q. Zhang. (2009). A contrastive study of compliment responses among Australian English and Mandarin Chinese speakers. Journal of Pragmatics. 41(2). pp. 325-345. Available: DOI: 10.1016/j.pragma.2008.05.019 
[4] D. Cheng. (2011). New insights on compliment responses: A comparison between native English speakers and Chinese L2 speakers. Journal of Pragmatics. 43(8). pp. 2204-2214. Available: https://doi.org/10.1016/j.pragma.2011.02.003

[5] G. L. Nelson, M. Al-Batal, and E. Echols. (1996). Arabic and English compliment responses: Potential for pragmatic failure. Applied Linguistics. 17(4). pp. 411-430. Available: https://doi.org/10.1093/applin/17.4.411

[6] H. Guo, Q. Zhou, and D. Chow. (2012). A variationist study of compliment responses in Chinese. International Journal of Applied Linguistics. 22(3). pp. 347-373. Available: https://doi.org/10.1111/j.1473-4192.2012.00315.x

[7] H. Spencer-Oatey, P. Ng, and L. Dong, "British and Chinese reactions to compliment responses," in Culturally Speaking: Culture, Communication and Politeness Theory, H. Spencer-Oatey, Ed. London \& New York: Continuum International Publishing Group, 2008, ch. 5, pp. 95-117.

[8] J. Holmes. (1988). Paying compliments: A sex-preferential politeness strategy. Journal of Pragmatics. 12(4). pp. 445465. Available: https://doi.org/10.1016/0378-2166(88)90005-7

[9] R. Chen. (1993). Responding to compliments: a contrastive study of politeness strategies between American English and Chinese speakers. Journal of Pragmatics. 20(1). pp. 49-75. Available: https://doi.org/10.1016/03782166(93)90106-YGet rights and content

[10] R. Chen, "Compliment and Compliment Response Research: A Cross-cultural Survey," in Pragmatics across Languages and Cultures, A. Trosborg, Ed. Berlin/New York: Walter de Gruyter GmbH \& Co. KG, 2010, pp. 79-111.

[11] S. E. Chen. (June 2003). Compliment response strategies in Mandarin Chinese: politeness phenomenon revisited. Concentric: Studies in English Literature and Linguistics. [Online]. 29(2). pp. 157-184. Available: http://www.concentric-linguistics.url.tw/upload/articlesfs111402103846150733.pdf

[12] Y. Yuan. (2002). Compliments and compliment responses in Kunming Chinese. Pragmatics. 12(2). pp. 183-226. Available: https://journals.linguisticsociety.org/elanguage/pragmatics/article/view/543.html 